\title{
No evidence of somatic aryl hydrocarbon receptor interacting protein mutations in sporadic endocrine neoplasia
}

\author{
A Raitila, M Georgitsi, A Karhu, K Tuppurainen ${ }^{1}, M^{\prime} J$ Mäkinen ${ }^{1}$, K Birkenkamp- \\ Demtröder $^{2}, K$ Salmenkivi ${ }^{3}$, T F Orntoft ${ }^{2}$, J Arola ${ }^{3}, V$ Launonen, $P$ Vahteristo \\ and $L A$ Aaltonen
}

\author{
Department of Medical Genetics, Biomedicum Helsinki, University of Helsinki, PO Box 63, Haartmaninkatu 8, FIN-00014 University \\ of Helsinki, Finland \\ ${ }^{1}$ Department of Pathology, University of Oulu, 90014 Oulu, Finland \\ ${ }^{2}$ Department of Clinical Biochemistry, Aarhus University Hospital/Skejby, 8200 Aarhus, Denmark \\ ${ }^{3}$ Department of Pathology, University of Helsinki and HUSLAB, 00014 Helsinki, Finland \\ (Correspondence should be addressed to L A Aaltonen; Email: lauri.aaltonen@ @elsinki.fi)
}

\begin{abstract}
Germline mutations in the aryl hydrocarbon receptor interacting protein $(A I P)$ gene were recently observed in patients with pituitary adenoma predisposition (PAP). Though AIP mutation-positive individuals with prolactin-, mixed growth hormone/prolactin-, and ACTH-producing pituitary adenomas as well as non-secreting pituitary adenomas have been reported, most mutationpositive patients have had growth hormone-producing adenomas diagnosed at relatively young age. Pituitary adenomas are also component tumors of some familial endocrine neoplasia syndromes such as multiple endocrine neoplasia type 1 (MEN1) and Carney complex (CNC). Genes underlying MEN1 and CNC are rarely mutated in sporadic pituitary adenomas, but more often in other lesions contributing to these two syndromes. Thus far, the occurrence of somatic AIP mutations has not been studied in endocrine tumors other than pituitary adenomas. Here, we have analyzed 32 pituitary adenomas and 79 other tumors of the endocrine system for somatic AIP mutations by direct sequencing. No somatic mutations were identified. However, two out of nine patients with prolactin-producing adenoma were shown to harbor a Finnish founder mutation (Q14X) with a complete loss of the wild-type allele in the tumors. These results are in agreement with previous studies in that prolactin-producing adenomas are component tumors in PAP. The data also support the previous finding that somatic AIP mutations are not common in pituitary adenomas and suggest that such mutations are rare in other endocrine tumors as well.
\end{abstract}

Endocrine-Related Cancer (2007) 14 901-906

\section{Introduction}

Germline mutations in the aryl hydrocarbon receptor interacting protein $(A I P)$ gene were recently reported in patients with pituitary adenoma predisposition (PAP; Vierimaa et al. 2006). Typically, individuals with germline AIP mutations display a young age at disease onset and growth hormone (GH)-producing pituitary adenomas, though patients with prolactin (PRL)- or aderenocorticotropic hormone (ACTH)-producing adenomas and non-secreting pituitary adenomas have been identified as well (Vierimaa et al. 2006, Barlier et al. 2007, Daly et al. 2007, Georgitsi et al. 2007b, Iwata et al.
2007, Toledo et al. 2007). Although many cases show family history of pituitary adenoma, in some cases the family history is weak or absent indicating incomplete penetrance (Vierimaa et al. 2006, Barlier et al. 2007, Daly et al. 2007, Georgitsi et al. 2007b). However, the highest AIP mutation frequencies have been observed in patients with family history of pituitary adenomas $(15 \%$ in familial isolated pituitary adenoma (FIPA) patients and up to $50 \%$ in those with familial GH-producing adenomas) when compared with patients with sporadic tumors (0-7.4\%) (Vierimaa et al. 2006, Yu et al. 2006, Barlier et al. 2007, Daly et al. 2007, Georgitsi et al. 2007b). Interestingly, the same AIP mutation can 
associate with different tumor types in different families, and the phenotype can vary even between family members (Vierimaa et al. 2006, Daly et al. 2007). Heterogeneity in immunohistochemical staining has also been observed; for instance, tumors from $\mathrm{GH}$-producing adenoma patients have shown only GH, GH and PRL, or $\mathrm{GH}$ and follicle-stimulating hormone (FSH) staining (Vierimaa et al. 2006, Daly et al. 2007). Tumor diameter has also been suggested to be larger in AIP mutation carriers when compared with non-carriers (Daly et al. 2007), although this was not detected in Finnish patients with PAP (Vierimaa et al. 2006).

Pituitary adenomas are component tumors in wellcharacterized endocrine neoplasia syndromes multiple endocrine neoplasia type 1 (MEN1) and Carney complex (CNC; Thakker 1998, Stratakis et al. 2001). The major predisposition genes for these syndromes are MEN1 and the protein kinase A regulatory subunit1- $\alpha$ (PRKARIA) respectively (Chandrasekharappa et al. 1997, Lemmens et al. 1997, Casey et al. 2000, Kirschner et al. 2000). Besides pituitary adenomas, MEN1 and CNC patients have tumors also in other endocrine glands. MEN1 lesions include parathyroid adenomas, entero-pancreatic islet tumors, adrenal cortical lesions, and foregut carcinoids, whereas in $\mathrm{CNC}$ heart and skin myxomas, primary pigmented nodular adrenocortical disease (PPNAD), testicular neoplasms, thyroid follicular adenomas or carcinomas, and ovarian cysts are common (Thakker 1998, Stratakis et al. 2001). Interestingly, MEN1 and PRKARIA are only rarely mutated in sporadic pituitary adenomas, but instead mutations have been detected in some of the other contributing lesions (Leotlela et al. 2003, Kaltsas et al. 2004, Boikos \& Stratakis 2006).

We have recently examined the occurrence of somatic AIP mutations in common cancers, with negative results (Georgitsi et al. 2007a). Thus far, no somatic mutations have been identified in pituitary adenomas either when studied by direct sequencing. Instead, loss of heterozygosity ( $\mathrm{LOH}$ ) has been detected in pituitary tumors as a second hit, the first being a germline mutation in the other allele (Barlier et al. 2007, Iwata et al. 2007, Georgitsi et al. 2007b). In this work, we sought for somatic AIP mutations also in non-pituitary endocrine tumors. The whole coding region of $A I P$ was analyzed in 32 sporadic pituitary adenomas and 79 other sporadic endocrine tumors.

\section{Subjects and methods}

\section{Patient characteristics}

Patient information and samples were obtained either after informed consent or with the permission from the
National Authority for Medicolegal Affairs. The study was approved by the appropriate ethics review committee.

Altogether 32 pituitary adenomas, of which nine were PRL-producing adenomas and $23 \mathrm{GH}$-producing adenomas, were included in the study (Table 1). The PRL-producing adenomas were from patients diagnosed at the Department of Pathology, Oulu University Hospital, Northern Finland. Immunohistochemistry for hypophyseal hormones was performed as a routine diagnostic procedure. All adenomas were positive for PRL and three adenomas stained positively also for GH. Tumor percentage, i.e. the percentage of tumor tissue in the sample, was determined according to a pathologist's histological evaluation and ranged between 70 and $90 \%$. Age at operation ranged between 35 and 64 years (mean age 49 years \pm 10.4 ). Sex distribution was five females and four males.

Out of the $23 \mathrm{GH}$-producing adenomas in the study, 21 belong to the population-based series of 54 Finnish acromegaly patients diagnosed at five university hospitals in Finland during 1980-1999 (KauppinenMakelin et al. 2005, Vierimaa et al. 2006). In addition, adenomas from two unselected Finnish sporadic acromegaly patients from Oulu region were included in this study. We had previously performed germline AIP mutation analysis in 20 patients from whom normal tissue was available; the results were negative (Vierimaa et al. 2006). Tumor percentage of the 22 tumors was determined according to a pathologist's histological evaluation, ranging between 75 and $90 \%$, except one with $20 \%$. For one case, information on tumor percentage was not available. Age at diagnosis ranged between 17 and 66 years (mean age 40 years $\pm 12.4)$. Age was not available for one patient. Ten patients were females and 13 were males.

A total of 79 other tumors of the endocrine system were available for this study (Table 1). Out of these, 61 tumors from 60 individuals were provided by the Department of Pathology, Helsinki University Central Hospital, Finland. Tumor percentage was determined according to a pathologist's histological evaluation, 56 tumors with $60-100 \%$ and five tumors with $30-40 \%$. Age at diagnosis ranged between 22 and 87 years (mean age 51 years \pm 15.5 ). Information on sex was available for 59 cases, of which 37 were females and 22 were males. One male individual had two tumors of the thyroid gland: one follicular adenoma and one papillary carcinoma. Corresponding normal tissue was available from 59 out of 61 cases. The remaining 18 endocrine tumors were provided by the Molecular Diagnostics Laboratory of the Department of Clinical Biochemistry, Aarhus University Hospital, Denmark. Corresponding 
Table 1 Pituitary adenomas and other endocrine tumors studied for somatic mutations in the aryl hydrocarbon receptor-interacting protein $(A I P)$ gene, and identified changes

\begin{tabular}{|c|c|c|c|c|}
\hline Endocrine tumors & $\begin{array}{c}\text { Number of tumors } \\
\text { analyzed }\end{array}$ & AIP change ch $^{a}$ & $\begin{array}{c}\text { Number of patients } \\
\text { with AIP change } \\
(\%)\end{array}$ & Healthy controls \\
\hline Pituitary adenomas & 32 & & & \\
\hline Prolactin producing & 9 & Q14X, 40C > T & $2(22.2 \%)$ & $0 / 532^{b}$ \\
\hline Growth hormone producing & 23 & & & \\
\hline Other endocrine tumors & 79 & & & \\
\hline Paragangliomas & 4 & & & \\
\hline Pancreatic endocrine tumors & 4 & & & \\
\hline Parathyroid gland & 8 & & & \\
\hline Adenomas & 6 & & & \\
\hline Carcinomas & 2 & & & \\
\hline Adrenal gland & 19 & & & \\
\hline Pheochromocytomas & 8 & & & \\
\hline Adrenal cortical adenomas & 7 & & & \\
\hline Adrenal cortical carcinomas & 4 & & & \\
\hline Thyroid gland & 26 & & & \\
\hline Follicular adenomas & 5 & G23E, 68G $>A$ & $1(3.8 \%)$ & $5 / 532^{b}$ \\
\hline Follicular carcinomas & 7 & & & \\
\hline Papillary carcinomas & 11 & & & \\
\hline Medullary carcinomas & 3 & & & \\
\hline Neuroendocrine tumors (carcinoids) & 16 & & & \\
\hline Lung & 1 & & & \\
\hline Cecum & 2 & & & \\
\hline Appendix & 4 & & & \\
\hline Small intestine & 9 & & & \\
\hline $\begin{array}{l}\text { Mixed endocrine-exocrine tumors } \\
\text { (adenocarcinoids) }\end{array}$ & 2 & & & \\
\hline Appendix & 1 & & & \\
\hline Cecum & 1 & & & \\
\hline
\end{tabular}

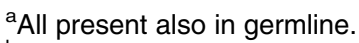

${ }^{\mathrm{b}}$ Controls have been analyzed in our previous studies (Vierimaa et al. 2006, Georgitsi et al. 2007a,b).

normal tissue, adjacent to the tumor, was available in 7 out of 18 cases. Age at diagnosis ranged between 18 and 77 years (mean age 53 years \pm 17.7 ). Sex distribution was 13 females and five males.

\section{Mutation analysis}

DNA was extracted from blocks of paraffin-embedded tissue according to standard procedures. The coding region and flanking intronic sequences of $A I P$ were amplified by PCR and analyzed by genomic sequencing as previously described (Vierimaa et al. 2006). Poor quality DNA was amplified in shorter fragments, for which the primer sequences and protocols are available upon request. The PCR products were purified using ExoSAP-IT PCR purification kit (USB Corporation, Cleveland, OH, USA), and the sequencing reactions were performed using the Big Dye 3.1 Termination chemistry on an ABI3730 DNA sequencer (Applied Biosystems, Foster City, CA, USA). Mutation analysis was initially performed on tumor samples, and the presence of all the observed changes was studied in the respective normal tissue, whenever available.

\section{Results}

Altogether 111 tumors were analyzed for somatic AIP mutations. In total, 1080 out of 1110 (97\%) fragments were successful in the analysis.

The Finnish founder mutation (Q14X, 40CT) was detected in two PRL-producing adenomas. Both tumors showed complete loss of the wild-type allele (Fig. 1). One mutation carrier was diagnosed with PRLproducing adenoma at the age of 35 years. The mutation was also detected in the germline. This male patient did not have family history of endocrine tumors. The other Q14X-positive individual was a female patient diagnosed with PRL-producing adenoma at the age of 35 years. Though secretion of PRL predominated the clinical phenotype, she also displayed features somewhat compatible with early signs of acromegaly. 

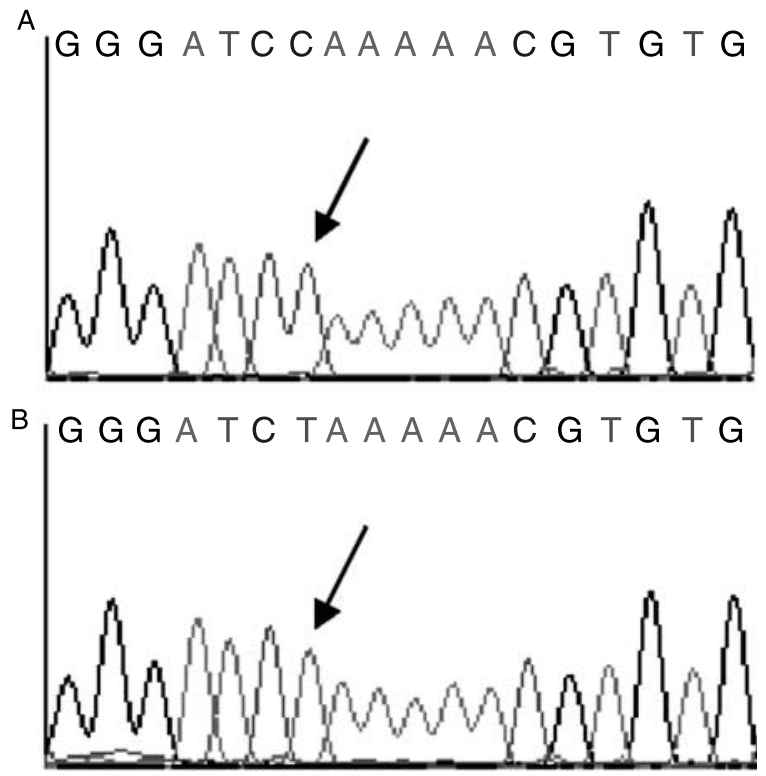

Figure 1 Electropherograms showing the AIP mutation are seen in two prolactin-producing adenomas. (A) The corresponding wild-type sequence (B) The AIP germline mutation $(\mathrm{Q} 14 \mathrm{X}, 40 \mathrm{C}>\mathrm{T})$ found in two prolactin-producing adenomas with loss of the wild-type allele in the tumor tissue. The mutated base is indicated by arrows.

Immunohistochemistry confirmed a mixed PRL/GHproducing tumor. Unfortunately, no normal tissue or information on the family history was available. Mutation screening of the $23 \mathrm{GH}$-producing adenomas did not reveal any changes in the AIP gene.

The only AIP change detected in the other endocrine tumors was a missense heterozygous change $(\mathrm{G} 23 \mathrm{E}$, $68 \mathrm{G}>\mathrm{A}$ ) in one individual. This female patient was diagnosed with follicular adenoma of the thyroid gland at the age of 60 years. No LOH was observed in the tumor sample, and the change was present also in the corresponding normal tissue. We have previously observed this change in 6 out of $373(1.6 \%)$ Finnish colorectal cancer samples and also in 5 out of 532 $(0.9 \%)$ unrelated, anonymous control samples of different origin (Vierimaa et al. 2006, Georgitsi et al. $2007 a, b)$. Although the G23 is highly conserved among species, the presently available data are more compatible with a germline polymorphism than with a pathogenic mutation.

\section{Discussion}

Germline mutations in the AIP gene have been associated with genetic predisposition to pituitary adenomas (Vierimaa et al. 2006). Most mutationpositive patients have had GH-producing tumors, but patients with PRL- and ACTH-producing adenomas as well as non-secreting tumors have also been reported (Vierimaa et al. 2006, Barlier et al. 2007, Daly et al. 2007, Georgitsi et al. 2007b, Toledo et al. 2007, Iwata et al. 2007). To date, no somatic AIP mutations have been identified in pituitary adenomas or in any other tumor type studied (Iwata et al. 2007, Barlier et al. 2007, Georgitsi et al. 2007a,b). In addition to pituitary adenomas, the present work focused on analyzing somatic AIP mutations also in other types of endocrine tumors.

No somatic AIP mutations were observed in any of the tumors studied. However, one pathogenic mutation (Q14X) was detected in two patients with PRLproducing adenomas (two out of nine, 22\%). This mutation is a Finnish founder mutation that has been detected in both familial setting as well as in patients with seemingly sporadic tumors (Vierimaa et al. 2006, Georgitsi et al. 2007b). Haplotype analysis has revealed that all the individuals studied share a common haplotype, confirming a common origin of the mutation (Vierimaa et al. 2006, unpublished data). In this study, the mutation was confirmed to be in the germline in the male mutation carrier patient. Both mutation-positive individuals have been diagnosed at the age of 35 years and the patient from whom information was available has no family history of endocrine tumors. Our results support previous observations that individuals with AIP mutations are diagnosed at a relatively early age. These individuals usually do not display a strong family history of pituitary adenomas, and that besides GH-producing adenomas, AIP mutations predispose also to PRL-producing adenomas which thus are part of the PAP phenotype (Vierimaa et al. 2006, Daly et al. 2007, this study).

Although PRL-producing adenomas are the most common pituitary adenomas (Arafah \& Nasrallah 2001), only a few tumors have thus far been analyzed for somatic AIP mutations. One obvious reason for this is that these tumors are only infrequently surgically removed as they have a low growth rate and a good response to drug treatment (Spada et al. 2005). Therefore, further studies are needed to clarify the possible role of somatic AIP mutations in PRLproducing adenomas.

No somatic mutations were detected in any of the 23 GH-producing pituitary adenomas studied. This is in agreement with the previous studies, suggesting that somatic AIP mutations do not have a major contribution in the genesis of these tumors (Barlier et al. 2007, Iwata et al. 2007). Overall, this is not surprising, as many tumor susceptibility genes are only rarely somatically mutated in the respective sporadic tumors; for instance, somatic mutations in the two major breast 
and ovarian cancer susceptibility genes BRCA1/2 are rare in breast tumors (Khoo et al. 1999, Yang et al. 2002).

No AIP mutations were detected in any of the 79 non-pituitary endocrine tumors studied here. Thus far, pituitary adenomas are the only tumors known to associate with AIP mutations. In contrast, in MEN1 syndrome pituitary neoplasia affects only $\sim 30 \%$ of patients, whereas primary hyperparathyroidism $(\sim 95 \%)$ and pancreatic islet cell tumors $(\sim 40 \%)$ are the major clinical manifestations (Thakker 1998). Additionally, in CNC pituitary adenomas are relatively rare ( $\sim 10 \%$ of patients) and the most common features are myxomas $(\sim 45 \%)$, PPNAD $(\sim 26 \%)$, schwannomas, testicular neoplasms, and thyroid adenomas or carcinomas (Stratakis et al. 2001). MENl and PRKARIA are not frequently mutated in sporadic pituitary adenomas, but somatic mutations have been detected in some other endocrine lesions, such as MEN1 mutations in sporadic foregut endocrine tumors, parathyroid tumors, endocrine tumors of the pancreas, and lung carcinoids, and PRKARIA mutations in thyroid and adrenal neoplasms (Leotlela et al. 2003, Kaltsas et al. 2004, Boikos \& Stratakis 2006).

Our results are in agreement with previous studies in that somatic mutations seem rare in pituitary adenomas (Barlier et al. 2007, Georgitsi et al. 2007b, Iwata et al. 2007). According to this study, such mutations appear uncommon also in non-pituitary endocrine tumors. We have also examined the contribution of AIP in common cancers with negative results (Georgitsi et al. 2007a). Taken together, this suggests that somatic AIP mutations are rare, and that thus far the only tumors associated with AIP mutations are pituitary adenomas.

\section{Acknowledgements}

All patients are greatly acknowledged for their valuable help. We are grateful to S Marttinen and I Vuoristo for their excellent technical assistance, $\mathrm{P}$ Ellonen for providing sequencing facilities and service. This study was supported by the Academy of Finland (grants 213183 to V Launonen, 212901 to P Vahteristo, the Center of Excellence in Translational GenomeScale Biology), the Sigrid Jusélius Foundation, the Cancer Society of Finland, the Association for International Cancer Research (grant 05-001 to A Karhu), the Jalmari and Rauha Ahokas Foundation (grant to M Georgitsi), and the Bodossaki Foundation (grant to M Georgitsi). The authors declare that there is no conflict of interest that would prejudice the impartiality of this scientific work.

\section{References}

Arafah BM \& Nasrallah MP 2001 Pituitary tumors: pathophysiology, clinical manifestations and management. Endocrine-Related Cancer 8 287-305.

Barlier A, Vanbellinghen JF, Daly AF, Silvy M, Jaffrain-Rea ML, Trouillas J, Tamagno G, Cazabat L, Bours V, Brue T, et al. 2007 Mutations in the aryl hydrocarbon receptor interacting protein gene are not highly prevalent among subjects with sporadic pituitary adenomas. Journal of Clinical Endocrinology and Metabolism 92 1952-1955.

Boikos SA \& Stratakis CA 2006 Carney complex: pathology and molecular genetics. Neuroendocrinology 83 189-199.

Casey M, Vaughan CJ, He J, Hatcher CJ, Winter JM, Weremowicz S, Montgomery K, Kucherlapati R, Morton CC \& Basson CT 2000 Mutations in the protein kinase A $\mathrm{R} 1$ alpha regulatory subunit cause familial cardiac myxomas and Carney complex. Journal of Clinical Investigation $106 \mathrm{R} 31-\mathrm{R} 38$.

Chandrasekharappa SC, Guru SC, Manickam P, Olufemi SE, Collins FS, Emmert-Buck MR, Debelenko LV, Zhuang Z, Lubensky IA, Liotta LA et al. 1997 Positional cloning of the gene for multiple endocrine neoplasia-type 1. Science 276 404-407.

Daly AF, Vanbellinghen JF, Khoo SK, Jaffrain-Rea ML, Naves LA, Guitelman MA, Murat A, Emy P, GimenezRoqueplo AP, Tamburrano G et al. 2007 Aryl hydrocarbon receptor interacting protein gene mutations in familial isolated pituitary adenomas: analysis in 73 families. Journal of Clinical Endocrinology and Metabolism 92 1891-1896.

Georgitsi M, Karhu A, Winqvist R, Visakorpi T, Waltering K, Vahteristo P, Launonen V \& Aaltonen LA 2007a Mutation analysis of aryl hydrocarbon receptor interacting protein $(A I P)$ gene in colorectal, breast, and prostate cancers. British Journal of Cancer 96 352-356.

Georgitsi M, Raitila A, Karhu A, Tuppurainen K, Mäkinen MJ, Vierimaa O, Paschke R, Saeger W, van der Luijt RB, Sane T et al. $2007 \mathrm{~b}$ Molecular diagnosis of pituitary adenoma predisposition, caused by aryl hydrocarbon receptor interacting protein gene mutations. PNAS 104 4101-4105.

Iwata T, Yamada S, Mizusawa N, Golam HMD, Sano T \& Yoshimoto K 2007 The aryl hydrocarbon receptor-interacting protein gene is rarely mutated in sporadic GH-secreting adenomas. Clinical Endocrinology 66 499-502.

Kaltsas GA, Besser GM \& Grossman AB 2004 The diagnosis and medical management of advanced neuroendocrine tumors. Endocrine Reviews 25 458-511.

Kauppinen-Makelin R, Sane T, Reunanen A, Valimaki MJ, Niskanen L, Markkanen H, Loyttyniemi E, Ebeling T, Jaatinen P, Laine $\mathrm{H}$ et al. 2005 A nationwide survey of mortality in acromegaly. Journal of Clinical Endocrinology and Metabolism 90 4081-4086.

Khoo US, Ozcelik H, Cheung AN, Chow LW, Ngan HY, Done SJ, Liang AC, Chan VW, Au GK, Ng WF et al. 1999 Somatic mutations in the BRCA1 gene in Chinese sporadic breast and ovarian cancer. Oncogene 18 4643-4646. 
Kirschner LS, Carney JA, Pack SD, Taymans SE, Giatzakis C, Cho YS, Cho-Chung YS \& Stratakis CA 2000 Mutations of the gene encoding the protein kinase A type I-alpha regulatory subunit in patients with the Carney complex. Nature Genetics 26 89-92.

Lemmens I, Van de Ven WJ, Kas K, Zhang CX, Giraud S, Wautot V, Buisson N, De Witte K, Salandre J, Lenoir G et al. 1997 Identification of the multiple endocrine neoplasia type 1 (MEN1) gene. The European Consortium on MEN1. Human Molecular Genetics 6 1177-1183.

Leotlela PD, Jauch A, Holtgreve-Grez H \& Thakker RV 2003 Genetics of neuroendocrine and carcinoid tumours. Endocrine-Related Cancer 10 437-450.

Spada A, Mantovani G \& Lania A 2005 Pathogenesis of prolactinomas. Pituitary 8 7-15.

Stratakis CA, Kirschner LS \& Carney JA 2001 Clinical and molecular features of the Carney complex: diagnostic criteria and recommendations for patient evaluation. Journal of Clinical Endocrinology and Metabolism 86 4041-4046.
Thakker RV 1998 Multiple endocrine neoplasia-syndromes of the twentieth century. Journal of Clinical Endocrinology and Metabolism 83 2617-2620.

Toledo RA, Lourenco DM Jr, Liberman B, Cunha-Neto MB, Cavalcanti MG, Moyses CB, Toledo SP \& Dahia PL 2007 Germline mutation in the Aryl hydrocarbon receptor interacting protein $(A I P)$ gene in familial somatotropinoma. Journal of Clinical Endocrinology and Metabolism 92 1934-1937.

Vierimaa O, Georgitsi M, Lehtonen R, Vahteristo P, Kokko A, Raitila A, Tuppurainen K, Ebeling TM, Salmela PI, Paschke $\mathrm{R}$ et al. 2006 Pituitary adenoma predisposition caused by germline mutations in the AIP gene. Science 312 1228-1230.

Yang Q, Yoshimura G, Nakamura M, Nakamura Y, Suzuma T, Umemura T, Mori I, Sakurai T \& Kakudo K 2002 BRCA1 in non-inherited breast carcinomas (Review). Oncology Reports 9 1329-1333.

Yu R, Bonert V, Saporta I, Raffel LJ \& Melmed S 2006 Aryl hydrocarbon receptor interacting protein variants in sporadic pituitary adenomas. Journal of Clinical Endocrinology and Metabolism 91 5126-5129. 